\title{
In utero exposure to diesel exhaust particles induces anxiogenic effects on male offspring via chronic activation of serotonergic neuron in dorsal raphe nucleus
}

\author{
Satoshi Yokota ${ }^{1,2}$, Shigeru Oshio ${ }^{2}$ and Ken Takeda ${ }^{1}$ \\ ${ }^{I}$ The Center for Environmental Health Science for the Next Generation, Research Institute for Science and \\ Technology, Organization for Research Advancement, Tokyo University of Science, \\ 2641 Yamazaki, Noda, Chiba 278-8510, Japan \\ ${ }^{2}$ Department of Hygiene Chemistry, School of Pharmaceutical Sciences, Ohu University, \\ 31-3 Misumido, Tomita, Koriyama, Fukushima 963-8611, Japan
}

(Received May 21, 2016; Accepted July 8, 2016)

\begin{abstract}
Diesel exhaust consists of diesel exhaust particles (DEPs) and gaseous compounds. Because previous research suggested that in utero exposure to DEPs affected spatial learning and memory in male offspring, while epidemiological evidence suggested disturbances in affect after prenatal exposure to particulates, we hypothesized that DEP exposure during pregnancy might also disturb affect. Here, we explored the effects of in utero exposure to DEPs on anxiety in male ICR mice. DEP solutions were administered subcutaneously to pregnant ICR mice at a dose of 0 or $200 \mu \mathrm{g} / \mathrm{kg}$ body weight on gestation days $6,9,12,15$, and 18 . We assessed anxiety in 6 week-old male offspring using the hole board test and elevated plus maze test. After the behavioral tests, animals were sacrificed and serotonin (5-HT) levels in the dorsal raphe nucleus (DRN) were measured using HPLC. Mice exposed to DEPs in utero demonstrated increased anxiety in both behavioral tests. HPLC analysis revealed a significant increase in 5-HT levels in the DRN. Double immunolabeling of the DRN using anti-5-HT and anti-FosB (a chronic neuronal activation marker) antibodies indicated chronic activation of the DRN might underlie the increased anxiety after prenatal DEP exposure.
\end{abstract}

Key words: Diesel exhaust particles, Prenatal exposure, Anxiety, Dorsal raphe nucleus, Serotonin

\section{INTRODUCTION}

Air pollutant exposure during pregnancy and early life was associated with a higher risk of neurodevelopmental disorders such as anxiety and depression (Perera et al., 2012). In particular, epidemiological studies suggested that pre- and post-natal exposure to traffic air pollutants, including high concentrations of particulate matter (PM), could increase susceptibility for the onset of neurodevelopmental disorders (Becerra et al., 2013; Kalkbrenner et al., 2015). Animal research also demonstrated that in utero exposure to both PM and stress induced anxietylike behavior and impaired cognition of male offspring (Bolton et al., 2013).

Vehicle-derived PM is a large component of diesel exhaust (DE) (Wichmann, 2007). DE is a complex mixture of diesel exhaust particles (DEPs) and gase- ous-phase compounds. The soluble organic fraction of PM in DE contains more than 1000 compounds, including polycyclic aromatic hydrocarbons and heavy metals (Wichmann, 2007). The International Agency for Research on Cancer, part of the World Health Organization, assigned DE as a Group 1 carcinogen in humans, with unambiguous evidence that exposure could increase the incidence of lung cancer (Silverman et al., 2012). However, whether DE exposure can induce neurodevelopmental disorders has yet to be elucidated.

Rodent models employing in utero exposure to DE or DEPs showed various postnatal consequences, including pathological effects on the cerebral cortex (Sugamata et al., 2006), decreased spontaneous motor activity (Suzuki et al., 2010; Yokota et al., 2009), dysfunction of motor coordination and induced impulsivity (Yokota et al., 2013b), and impairment of learning and

Correspondence: Satoshi Yokota (E-mail: satoshi_yokota1008@yahoo.co.jp; s-yokota@pha.ohu-u.ac.jp) 
memory (Yokota et al., 2015) of male offspring. However, despite DEPs being a major contributor to airborne PM, there have been no studies on whether in utero exposure to DE affects anxiety levels of offspring. Our previous study demonstrated that in utero exposure to high concentrations of DE altered serotonin (5-HT) levels in various brain regions (Yokota et al., 2013b) of male offspring. Such alterations could induce anxiety or other behavioral disturbances in the next generation (i.e., the offspring of the exposed dam).

It is well known that the neurotransmitter 5-HT regulates anxiety (Lucki, 1998), as evidenced by the many commonly used anti-anxiety medications that target this system (Barrett and Vanover, 1993). The dorsal raphe nucleus (DRN), as the origin of serotonergic projections to forebrain regions including the amygdala (Amy), helps regulate anxiety states and anxiety-related behavior (Campbell and Merchant, 2003; Graeff et al., 1996; Maier et al., 1993). Stimuli related to anxiety activate DRN 5-HT neurons (Commons, 2008; Hale et al., 2012; Kelly et al., 2011; Paul et al., 2011; Spannuth et al., 2011), so evaluating DRN serotonergic activation is important when studying the effects of toxicant substances on anxiety.

Our colleague found various pathologies in brain tissue samples in which DEP-like substances had accumulated following maternal exposure to DE (Sugamata et $a l ., 2006)$. Given the above body of research, we hypothesized that the serious health effects were caused mainly by the particulate components, DEPs. Thus, this study focused on the effects of exposure to DEPs, and specifically on examining the effects of prenatal exposure to DEPs with regard to 5-HT neuronal activation in the DRN and anxiety-like behavior in male offspring.

\section{MATERIALS AND METHODS}

\section{Characterization of diesel exhaust particles}

DEPs were analyzed as previously described (Yokota et al., 2015). Briefly, DEPs were collected with a constant volume sampler system equipped at the end of a dilution tunnel of a 2,369-cc diesel engine (Isuzu Motors, Ltd., Tokyo, Japan), which was operated at a speed of $1,050 \mathrm{rpm}$ at $80 \%$ load, with commercial diesel fuel. Equipment was provided by the Japan Anti-Tuberculosis Association (Tokyo, Japan). DEPs were suspended at $1 \mathrm{mg} / \mathrm{mL}$ in an isotonic sodium chloride solution ( $\mathrm{pH} 6.3$; Otsuka, Pharmaceutical Factory Inc., Tokushima, Japan) with $0.05 \%$ Tween 80 and were sonicated for approximately $30 \mathrm{~min}$ just before administration. To determine the size distribution of DEPs in suspension, DEPs were subjected to dynamic light scattering measurements using a Zetasizer Nano-ZS (Malvern Instruments Ltd, Worcestershire, UK). A DEP suspension was also passed through a 450-nm Millex-HV filter (SLHV033RS; Merck Millipore Ltd., Carrigtwohill, Cork, Ireland) and analyzed by dynamic light scattering to determine the size distribution in the absence of bulk aggregation. The DEPs consisted of elemental and organic carbons, metals and anions, and were various sizes (approximately 60-1700 nm in diameter), with a peak size of $126.0 \pm 36.6 \mathrm{~nm}$. DEP analysis also produced a polydispersity index of 0.629 \pm 0.015 in distribution, and an ultrafine DEP fraction in the suspension as determined by dynamic light scattering measurements using a Zetasizer Nano-ZS (Malvern Instruments Ltd, Worcestershire, UK).

\section{Animals and treatments}

The experimental design was the same as previously reported elsewhere (Fig. 1) (Yokota et al., 2015). Briefly, thirty pregnant ICR mice obtained from SLC Co. (Shizuoka, Japan) were used throughout the experiments. DEP suspensions (200 $\mu \mathrm{g} / \mathrm{kg}$ body weight) were injected subcutaneously into fifteen pregnant mice on gestation days $6,9,12,15$, and 18 , respectively. The total doses of DEPs were adjusted to approximately $1 \mathrm{mg} / \mathrm{kg}$ body weight. Dosing paradigm and route of exposure relevant to the human condition was intratracheal administration. In fact, a previous study reported a mouse model of a single intratracheal administration of DEP suspension mimicked DEP inhalation (Costa et al., 2010). However, intratracheal administration can cause a strong stress response because of restraint stress during administration. Repeated restraint stress to pregnant mice could confound the effect of DEPs. Furthermore, the effects of prenatal exposure to repeated anesthesia on offspring is also a major concern, as anesthesia is required for intratracheal administration. We wanted to investigate the effect of in utero exposure to DEPs on anxiety-like behavior of offspring because DEPs were accumulated in the same brain region such as cerebral cortex and hippocampus after DE inhalation or DEP subcutaneous injection (Sugamata et al., 2006). In addition, subcutaneous injection can be easily used for repeated treatments. Therefore, we selected subcutaneous injection of DEP suspensions into pregnant mice because of lower stress during pregnancy, and because a certain dose could be achieved. Saline (containing $0.05 \%$ Tween 80 ) was injected subcutaneously into other pregnant mice as a control. After DEP exposure, mothers and male pups were maintained in the same clean room. After weaning on postnatal day 21, male mice were maintained in groups in home cages (5 mice/ 
Fetal exposure to diesel exhaust particles induce anxiety-like behavior in male offspring

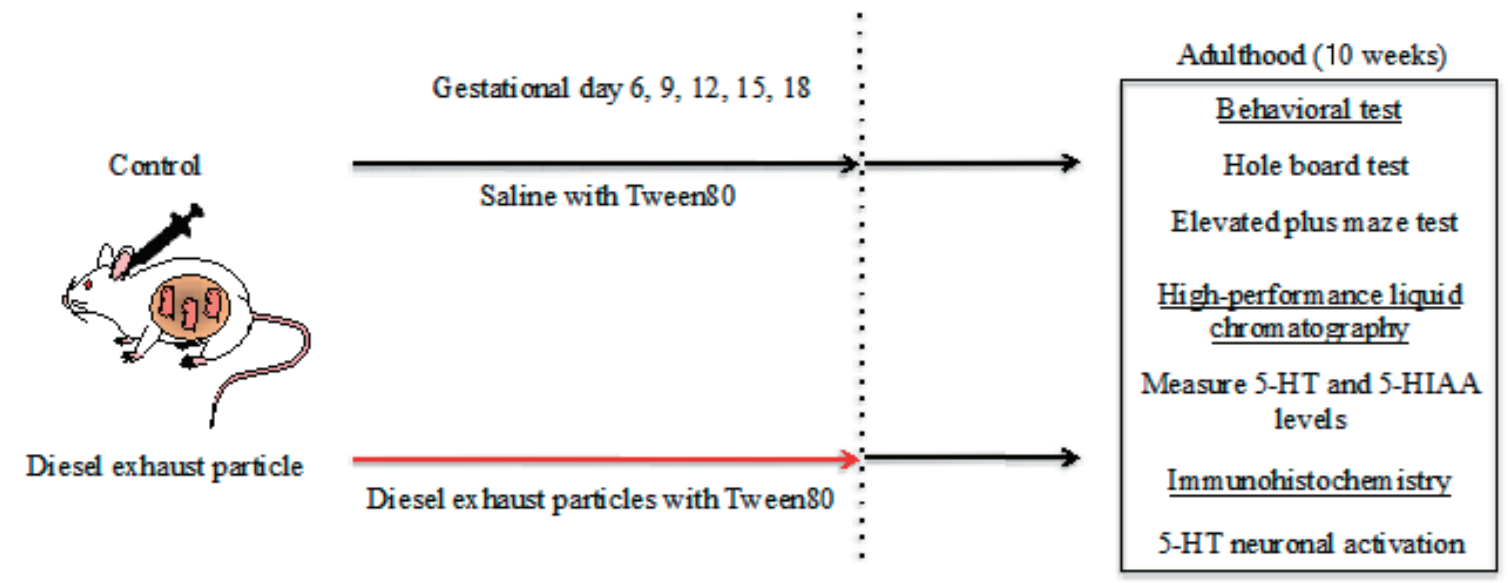

Fig. 1. Schematic diagram of the schedule of maternal exposure to diesel exhaust particles and the methods of analysis.

cage) at $22 \pm 2{ }^{\circ} \mathrm{C}$, in a humidity-controlled environment (50 $\pm 5 \%$ humidity) with a 12-hr light/dark cycle (lights on from 8:00 to 20:00). Food and water were provided ad libitum. Body weights of male mice were recorded at 6 (just before sample collection) weeks of age. When the pregnant mice were dissected, residues of DEP aggregates were apparent in the subcutaneous tissue. All experiments were performed in accordance with National Institutes of Health (NIH, USA) guidelines for animal experiments to minimize suffering and were approved by Tokyo University of Science's Institutional Animal Care and Use Committee (Experimental No.08-12).

\section{Behavioral testing}

Fifteen male offspring per group per endpoint $(n=30 /$ group total) were used for behavioral tests. All behavioral tests were conducted between 13:00 and 17:00, and the order of trials was counterbalanced among the control and DEP-exposed groups. All the experimental mice were transferred to the behavior testing room $30 \mathrm{~min}$ prior to beginning the first trial, for habituation to the behavior testing room. Behavioral tests, namely the hole board and elevated plus maze tests, were performed at 6 weeks of age. To avoid carryover effects between tests, each mouse was used independently in each behavioral test. This design does not change the interpretation of the results in the current set of experiments, as was previously described (Yokota et al., 2015). Behavioral scores were assessed by two observers blind to each exposure group.

\section{Hole board test}

Anxiety in male offspring ( 6 weeks of age) was measured using a modified hole board test (Takeda et al., 1998; Tsuji et al., 2000). The apparatus was a gray acrylic box $(50 \mathrm{~cm} \times 50 \mathrm{~cm} \times 50 \mathrm{~cm})$ with four equidistant holes $3 \mathrm{~cm}$ in diameter in the floor. The mouse was recorded for $5 \mathrm{~min}$ and the recorded data analyzed manually (two independent researchers) using a video camera. An infrared beam sensor was installed on the wall to detect the number of head-dipping behaviors and the latency time to the first head-dipping.

\section{Elevated plus maze test}

Anxiety was also measured using a modified elevated plus maze test (Holmes et al., 2000; Mosienko et al., 2012; Walf and Frye, 2007). The apparatus was constructed from black Plexiglas, elevated $40 \mathrm{~cm}$ above the floor, and consisted of two of open $(25 \times 5 \times 0.5 \mathrm{~cm})$ and two closed arms $(25 \times 5 \times 16 \mathrm{~cm})$ that extended from a central platform $(5 \times 5 \times 0.5 \mathrm{~cm})$. The open arms had a very small $(0.5 \mathrm{~cm})$ wall to decrease the number of falls, whereas the closed arms have a high $(16 \mathrm{~cm})$, enclosing wall. The test was initiated by placing the mouse on the central platform, facing the open arm opposite the experimenter, and starting video recording. Recording parameters and analysis were the same as described in 2.3.1. Time spent in the open arms was monitored with a stopwatch. Numbers of both open and closed arm entrances were also recorded. Arm entry was only defined when the mouse moved at least $3 \mathrm{~cm}$ into the arm, to differentiate entries from stretched attend postures. Total activity was recorded automatically by the video tracking system.

\section{High performance liquid chromatography (HPLC)}

After the elevated plus maze test, ten male offspring per group were used for HPLC analysis. Brain dissection was based on the atlas of Paxinos and Franklin 
(Paxinos and Franklin, 2001). Coronal slices $(300 \mu \mathrm{m})$ taken at $-0.70 \mathrm{~mm},-0.94 \mathrm{~mm}$, and $-4.60 \mathrm{~mm}$ from bregma were prepared using a microtome (Sakura Finetek Co., Ltd., Tokyo, Japan). The following four regions were dissected via micropunch (Harris Uni-Core, Electron Microscopy Sciences): the paraventricular nucleus of the hypothalamus (PVN, $-0.70 \mathrm{~mm}$ ); amygdala (Amy, $-0.94 \mathrm{~mm}$ ); dorsal raphe nucleus (DRN, -4.60 mm); and median raphe nucleus (MRN, $-4.60 \mathrm{~mm}$ ). Dissected tissue was homogenized in ice-cold 0.2 M perchloric acid (Nacalai Tesque Inc., Kyoto, Japan) containing $100 \mu \mathrm{M} \mathrm{Na}$-EDTA (Dojinto Laboratories, Kumamoto, Japan) and 10 pg isoproterenol as an internal standard (Sigma-Aldrich Co., St. Louis, MO, USA). The homogenates were kept on ice for $30 \mathrm{~min}$ and then centrifuged at $20,000 \mathrm{~g}$ at $4{ }^{\circ} \mathrm{C}$ for $15 \mathrm{~min}$. The supernatant was mixed with $1 \mathrm{M}$ sodium acetate to adjust the $\mathrm{pH}$ to 3.5 (Kanto Chemical Co., Inc., Tokyo, Japan) and was analyzed immediately. A $10 \mu \mathrm{L}$ sample of the final supernatant was injected with a microsyringe (702SNR; Hamilton Co., Reno, NV, USA) into an HPLC system equipped with an electrochemical detector (HTEC-500MAB; Eicom Co., Kyoto, Japan). The standard solution contained 5-HT and its metabolite, 5-hydroxyindole-3-acetic acid (5-HIAA) from SigmaAldrich. Compounds were separated by passage through a $\mathrm{C} 18$ reverse-phase column (Eicompak SC-5ODS; $3.0 \mathrm{~mm} \times 150 \mathrm{~mm}$; Eicom), maintained at $25^{\circ} \mathrm{C}$ and connected to an electrochemical detector (EPC-500, Eicom). The mobile phase was $0.1 \mathrm{M}$ acetic acid/citric acid buffer ( $\mathrm{pH} 3.5$ ) containing $\mathrm{Na}_{2}$-EDTA ( $5 \mathrm{mg} / \mathrm{L}$ ), octanesulfonic acid (190 mg/L; Nacalai Tesque), and methanol (15\% (v/v); Kanto Chemical Co., Inc.). The flow rate was maintained at $0.5 \mathrm{~mL} / \mathrm{min}$. Data were collected and analyzed with the PowerChrom 280 System (eDAQ Pty Ltd., New South Wales, Australia). Values in individual tissue samples were calculated based on the peak area, and compared to those of the internal standards. Concentrations of 5-HT and 5-HIAA were expressed as pg/unit. A unit was defined as an aliquot of each brain tissue sample (i.e., supernatant from a single micropunch sample).

\section{Perfusion and fixation}

After the elevated plus maze test, mice were anesthetized and perfused through the heart with phosphate buffered saline (PBS, pH7.4) followed immediately by a fixative containing $4 \%$ paraformaldehyde, $0.1 \%$ glutaraldehyde, and $0.2 \%$ picric acid in $0.1 \mathrm{M}$ PBS which was prepared just before use. Then, the brains were quickly removed after perfusion, and thick coronal sections of the midbrain including the DRN were initially dissected using a Brain Blocker (Electron Microscopy Sciences,
Inc., Hatfield, PA, USA), then postfixed in the same fixative solution without glutaraldehyde for $24 \mathrm{hr}$ at $4^{\circ} \mathrm{C}$, and finally placed in $30 \%$ phosphate-buffered sucrose at $4^{\circ} \mathrm{C}$.

\section{Immunohistochemistry}

Five male offspring per group were used for immunohistochemical analysis as previously described (Amemiya et al., 2010; Yanagita et al., 2007; Yokota et al., 2013a). Briefly, each tissue block was frozen, sectioned serially at $40 \mu \mathrm{m}$ thickness with a microtome (Sakura Finetek Co., Ltd.), and collected in 0.1 M PBS. Sections were treated with $0.3 \%$ hydrogen peroxide to block endogenous peroxidase and preincubated in 10\% normal horse serum. They were then rinsed with PBS, and then incubated in primary rabbit polyclonal anti-FosB antibody (sc-48, Santa Cruz Biotechnology, Inc., Santa Cruz, CA, USA), diluted 1:600 in 0.1 M PBS with $0.1 \%$ Triton X-100 (PBS-Tx), for $16 \mathrm{hr}$ at room temperature. After rinsing 3 times with PBS-Tx, the sections were further incubated in biotinylated donkey anti-rabbit IgG (AP182B, Millipore, Temecula, CA, USA, 1:800) for $2 \mathrm{hr}$ at room temperature, followed by 3 rinses with PBS-Tx. Finally, the sections were treated with avidin-biotin-peroxidase complex (Vectastain ABC peroxidase kit, Vector Laboratories Inc., Burlingame, CA, USA, 1:400) for $4 \mathrm{hr}$, and then reacted in a solution consisting of nickel ammonium sulfate, $0.02 \%$ 3,3-diaminobenzidine in $0.1 \mathrm{M}$ Tris- $\mathrm{HCl}$ buffer $(\mathrm{pH} 7.6)$, and $0.01 \% \mathrm{H}_{2} \mathrm{O}_{2}$ for $14 \mathrm{~min}$. For dual immunostaining for 5-HT, sections previously immunolabeled with anti-FosB antibodies and reacted with the chromogen above were subsequently incubated in primary rabbit polyclonal anti-5HT antibody (cat no. 20080, ImmunoStar, Inc., Hudson, CA, USA, 1:5000), followed by biotinylated secondary antibody solution, donkey anti-rabbit IgG (AP182B, Millipore, Temecula, CA, USA, 1:800). Avidin-biotin-peroxidase complex (Vectastain ABC peroxidase kit, Vector Laboratories Inc., Burlingame, CA, USA, 1:400) was visualized with $0.02 \% 3,3$-diaminobenzidine in $0.1 \mathrm{M}$ Tris$\mathrm{HCl}$ buffer ( $\mathrm{pH} 7.6$ ) without nickel sulfate, and $0.01 \%$ $\mathrm{H}_{2} \mathrm{O}_{2}$ for $30 \mathrm{~min}$. FosB immunoreactivity was localized to the cell nuclei and appeared as a dark gray-black stain, while 5-HT immunoreactivity was localized to the cell cytoplasm and visible as a brown stain. Subsequently, sections were washed in 0.01 M PBS, mounted on gelatin coated glass slides, air-dried, dehydrated in a graded series of alcohols, cleared in xylene, and coverslipped with Entellan (Merck Co, Ltd., Tokyo, Japan). Photomicrographs were captured with a light microscope (BX51; Olympus Co., Ltd., Tokyo, Japan). Quantitative analysis was performed on all sections containing the DRN. Total 
Fetal exposure to diesel exhaust particles induce anxiety-like behavior in male offspring

number of double-labeled cells for 5-HT and FosB was counted bilaterally in the DRN on sections between -4.03 and -5.33 from the bregma (Paxinos and Franlin, 2001). The percentage of FosB positive nuclei in 5-HT labeled cells was calculated in the DRN. These double labeled cells were identified by shape and color (overlapping between brown-colored 5-HT cell body and black-colored FosB positive nuclei).

\section{Statistical analysis}

We used independent litters for both behavioral and histochemical analyses. Independent litters were composed of one pup from each dam from the control or DEP-exposed groups. Statistics were performed with the independent litter as the statistical unit. Values for body weight, each behavioral test, and immunohistochemistry are presented as the mean \pm S.E. Student's t-test was used to detect significant differences between the control and DEP-exposed groups. Significance was accepted if $p<0.05$.

\section{RESULTS}

\section{Effects of prenatal exposure to DEPs on litter size and body weight}

As previously reported (Yokota et al., 2015), DEP exposure had no significant effects on litter size. The body weight of male offspring was not affected by maternal DEP exposure ( 6 weeks: Control, $35.0 \pm 0.4 \mathrm{~g}$ and DEP, $35.3 \pm 0.6 \mathrm{~g})$. No deaths or malformations were observed in either control or DEP-exposed mice.

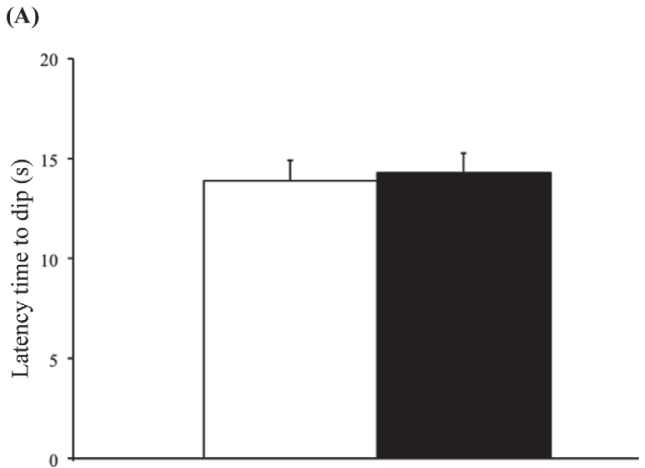

\section{Effects of prenatal DEP exposure on anxiety- related behaviors}

In the hole board test, DEP-exposed mice showed a significant decrease in the number of head-dipping behaviors compared to control mice, while there were no changes detected in latency time to head dipping (Fig. 2A, B). In the elevated plus maze test, DEP-exposed mice entered the open arms significantly fewer times (Fig. 3A), and spent significantly less time in the open arms (Fig. 3B), than did control mice. However, there were no significant differences in locomotion during the elevated plus maze test between control and DEP-exposed mice (Fig. 3C).

\section{Effects of prenatal DEP exposure on 5-HT and 5-HIAA levels}

Brain regions were dissected as shown in Fig. 4A. We found that prenatal exposure to DEPs significantly increased 5-HT levels, but not 5-HIAA levels, in the PVN (Fig. 4B). However, 5-HT and 5-HIAA concentrations in the Amy and MRN were not altered by prenatal DEP exposure (Fig. 4C, D). Both 5-HT and 5-HIAA levels in the DRN were significantly increased by in utero exposure to DEPs (Fig. 4E).

\section{Effects of prenatal DEP exposure on 5-HT neuronal activation in the DRN}

To begin to understand the mechanism underlying the increase in DRN 5-HT levels, we studied neuronal activation within the DRN immunohistochemically (Fig. 5A). Photomicrographs showed 5-HT positive cells as a cytoplasmic brown label, and FosB positive nuclei as a dark gray-black stain (Fig. 5B). The number of 5-HT neurons in the DRN of offspring was not altered by prena-

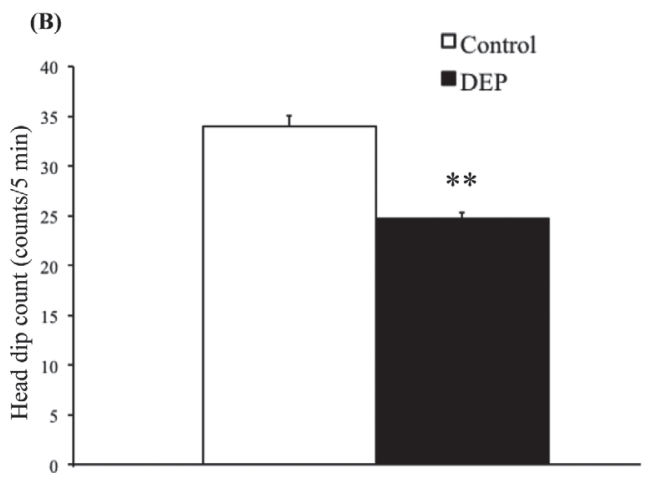

Fig. 2. Effect of prenatal DEP exposure on anxiety-like responses of mice in the hole board test. (A) DEP-exposed mice did not show significant effects on latency time to head dipping. (B) DEP-exposed mice showed a significant decrease in the number of head dippings. Each column represents the mean with standard error of 15 mice. ${ }^{* *} \mathrm{p}<0.01$ vs control. Abbreviations: DEP, diesel exhaust particle. 
(A)

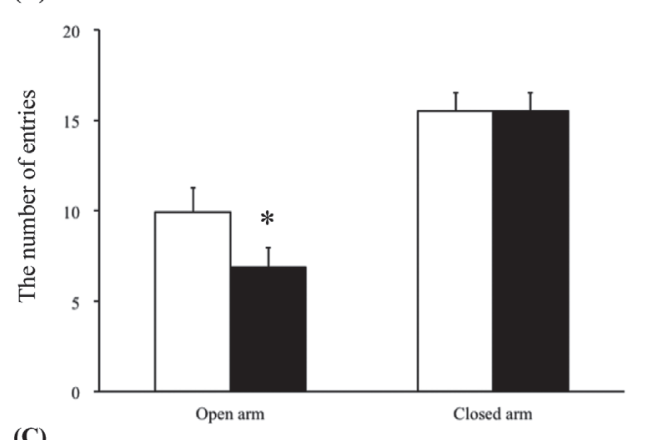

(C)

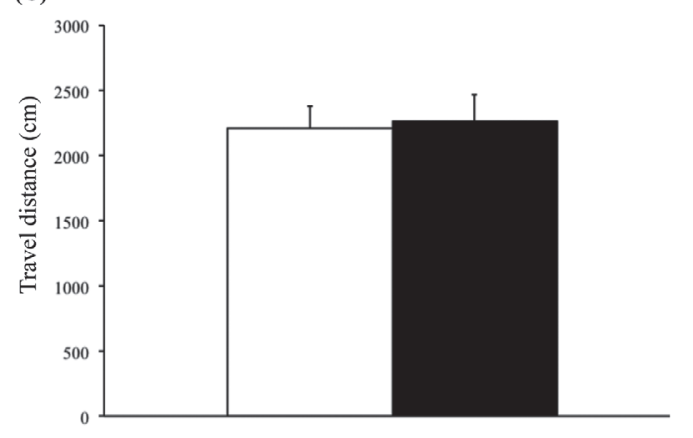

(B)

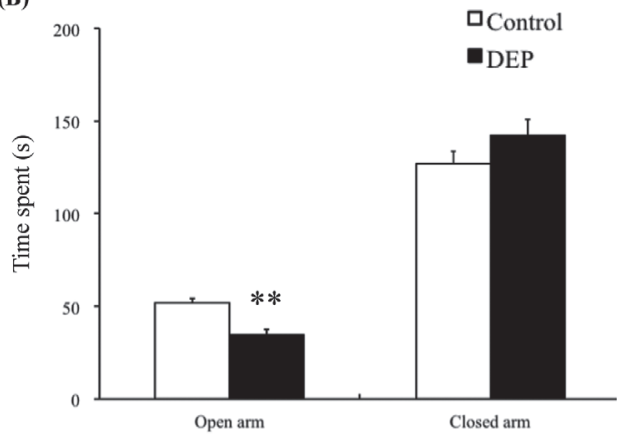

Fig. 3. Effect of prenatal DEP exposure on anxiety-like responses of mice in the elevated plus maze test. (A) The number of open arm entries was significantly reduced in DEP-exposed mice. In contrast, the number of closed arm entries was not changed in either group. (B) The time spent in the open arms was significantly reduced in DEP-exposed mice, whereas the time spent in the closed arms was not changed in either group. (C) No effect of DEP exposure was detected for the total distance travelled, an index of locomotor activity. Each column represents the mean with standard error of 15 mice. *p $<0.05$, $* * \mathrm{p}<0.01$ vs control. Abbreviations: DEP, diesel exhaust particle.

tal exposure to DEPs according to histochemical analysis (Fig. 5C), although the rate of double-labeled FosB- and 5-HT-immunoreactive cells in the DRN was significantly increased by prenatal exposure to DEPs (Fig. 5D).

\section{DISCUSSION}

The results of the present study demonstrate, for the first time, that prenatal DEP exposure increases anxietylike behavior in male offspring later in life, and increases 5-HT levels in the DRN via chronically increased 5-HT neuronal activity. On the other hand, the dose used in the present study did not affect litter size, body weight, or locomotion. Our data contribute to the body of work elucidating the numerous relationships between air pollutant exposure during pregnancy and mental disorders, including anxiety (Perera et al., 2012). Maternal environmental stressors such as stress itself, testosterone, and lipopolysaccharides enhanced anxiety-like behavior of offspring (Boulle et al., 2015; Hu et al., 2015; Solati et al., 2015). The maternal environment is very important in the devel- opment of the offspring, as several "critical periods" of central nervous system development occur during gestation. Our previous work demonstrated that prenatal exposure to DE affected locomotion (Suzuki et al., 2010; Yokota et al., 2013b; Yokota et al., 2009) and aggressive behavior (Yokota et al., 2016) in male offspring, and that prenatal exposure to DEPs (the same exposure as was used herein) impaired learning and memory, also in male offspring (Yokota et al., 2015).

To assess anxiety-like behavior, we used the hole board and elevated plus maze tests. In the hole board test, head-dipping behavior is related to exploratory behavior, and reduced numbers of head dips and increased latency to head-dipping are indicative of greater anxiety or anxiety-like behavior (Escorihuela et al., 1999). The DEPexposed mice herein had reduced numbers of head dips compared to control mice, which suggests that in utero exposure to DEPs exacerbated anxiety-like behavior in male offspring. Similar behavioral results were observed in the elevated plus maze test. Mice typically avoid the open arms and prefer the closed arms, whereas known 
Fetal exposure to diesel exhaust particles induce anxiety-like behavior in male offspring
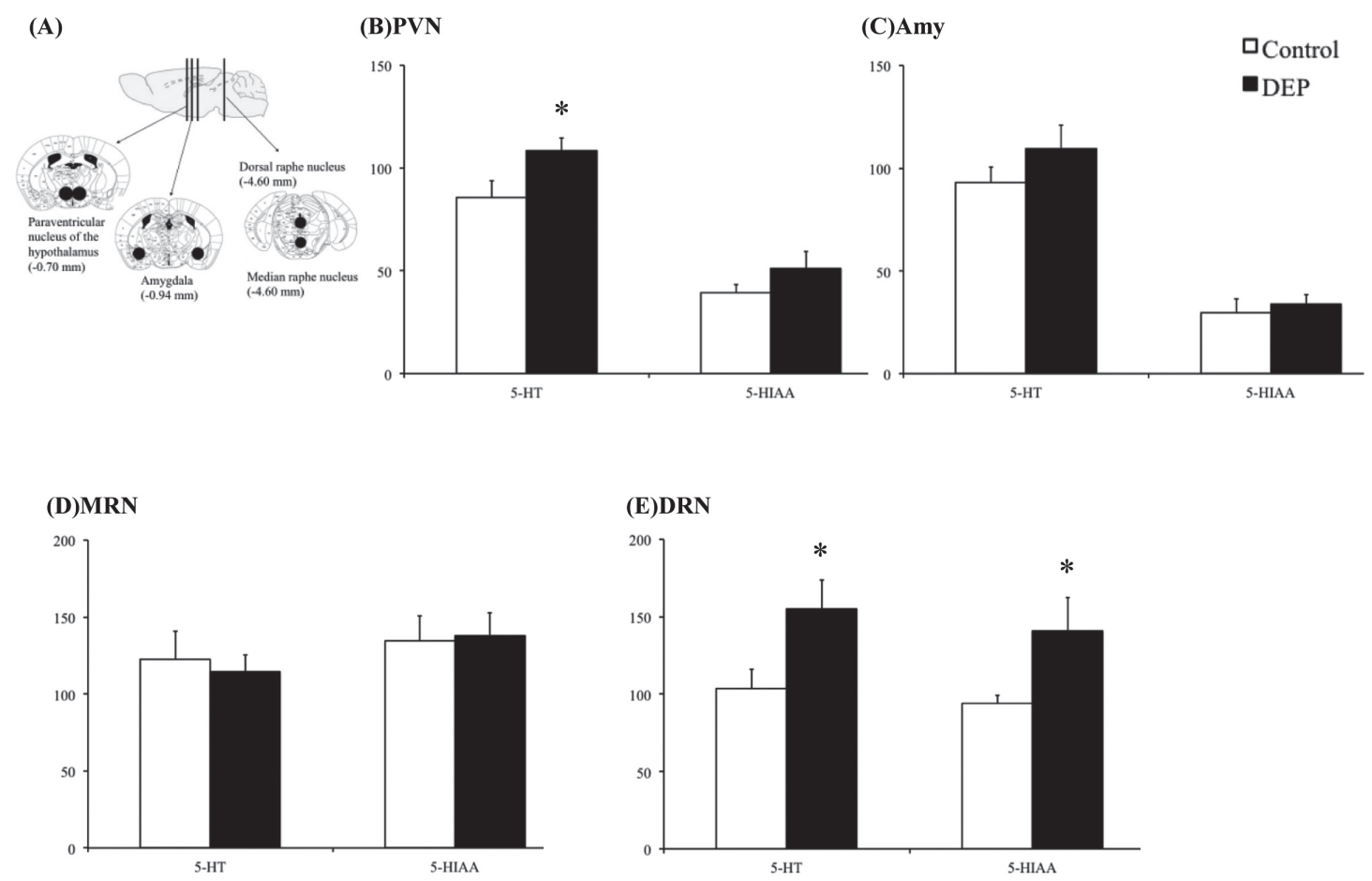

Fig. 4. Effects of prenatal DEP exposure on ascending 5-HT systems in male offspring. (A) Schematic diagram of the brain. The positions of dissection were shown. (B) Prenatal exposure to DEP significantly increased 5-HT levels, but not 5-HIAA levels, in the PVN. (C, D) No effect of DEP exposure was detected in either 5-HT or 5-HIAA levels in the Amy (C) and MRN (D). (E) Prenatal exposure to DEP significantly increased both 5-HT and 5-HIAA levels in the DRN. Each column represents the mean (pg/unit) with standard error of 10 mice. ${ }^{*} \mathrm{p}<0.05$ vs control. Abbreviations: 5-HT, serotonin; 5-HIAA, 5-hydroxyindole-3-acetic acid; Amy, amygdala; DEP, diesel exhaust particles; DRN, dorsal raphe nucleus; MRN, median raphe nucleus; PVN, paraventricular nucleus of the hypothalamus.

anxiolytic agents increase the time spent in open arms (Carobrez and Bertoglio, 2005). Thus, a decrease in the entry number and/or time spent in the open arms suggests an increase in anxiety. As with the hole board test, in utero exposure to DEPs increased anxiety-like behavior in the male offspring in the elevated plus maze test, including fewer open arm entries and time spent in the open arms compared to control mice. Importantly, there were no differences in entries and/or time spent in the closed arms, which indicates that general locomotor activity was similar between the control and DEP-exposed mice.

We have previously observed that DEPs were accumulated in various brain regions of DE-exposed mice (Sugamata et al., 2006). DEPs comprised more than 1,000 chemicals and some surface chemical compounds had estrogenic effects (Wichmann, 2007). Treatment with estradiol benzoate increased anxiety in mice (Morgan and Pfaff, 2001). In addition, estrogen substances may enhance brain-derived neurotrophic factor function, lead- ing to alterations in the serotonin circuits, which modulate anxiety-like behavior (Ren-Patterson et al., 2006). Therefore, DEPs may increase anxiety-like behavior with changes of serotonergic systems of mice via estrogenic effects of DEPs.

Second, to examine changes in 5-HT systems that could correlate with the increased anxiety-like behavior, we measured 5-HT and 5-HIAA levels in the brain using HPLC. Significantly increased 5-HT and 5-HIAA concentrations were observed in the DRN, one origin of nucleus of 5-HT systems in the central nervous system, and PVN, a projection site of 5-HT neurons emanating from the DRN, but not in the MRN, the other origin of nucleus of 5-HT systems in the central nervous system, of DEP-exposed mice. The brain 5-HT system has been strongly implicated in the neural regulation of anxiety state. In fact, a variety of behavioral tests revealed that stimulation of 5-HT autoreceptors induced anxiolytic effects (Graeff et al., 1998; Higgins et al., 1992; Hogg et 
(A)

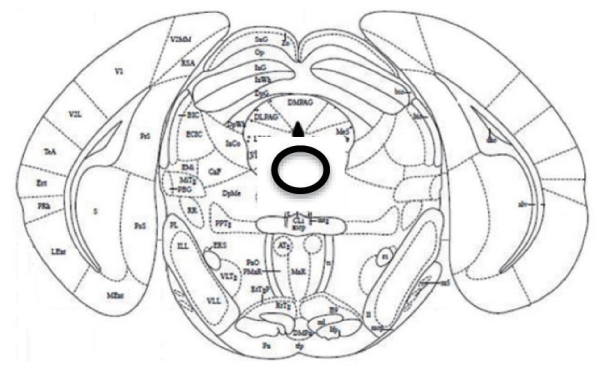

(C)

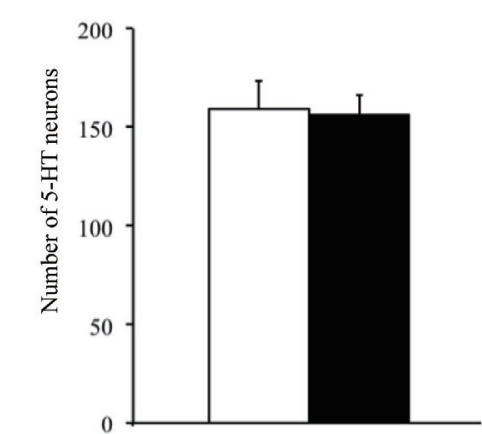

(B)

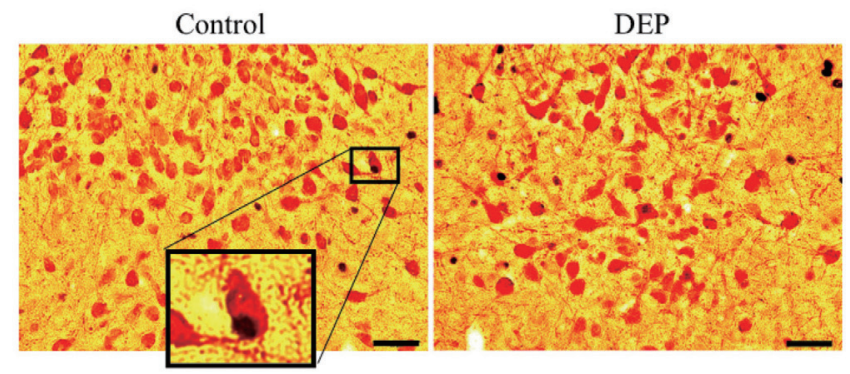

(D)

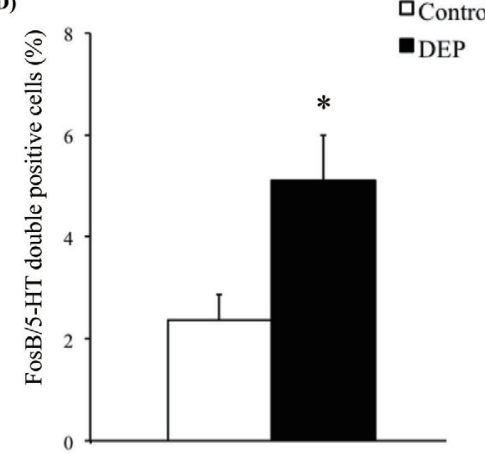

Fig. 5. Immunohistochemical analysis of 5-HT and FosB expression in the DRN. (A) Schematic diagram of the section (DRN: $-4.60 \mathrm{~mm}$ from the bregma). The black circle represents the area which was analyzed histochemically. (B) Expansion of (A), with images showing a representation of the immunostaining procedure that labeled 5-HT and FosB as brown and black, respectively [(Left) Control, (Right) DEP]. Scale bar $=50 \mu \mathrm{m} .(\mathrm{C})$ Each column represents the mean $( \pm$ standard error; SE) number of 5-HT-positive cells in the DRN of 5 mice. (D) Each column represents the mean $( \pm$ S.E.) rate (\%) of FosB-positive cells in the 5 -HT neurons in the DRN of 5 mice. ${ }^{*} \mathrm{p}<0.05$ vs control. Abbreviations: 5 -HT, serotonin; DEP, diesel exhaust particles; DRN, dorsal raphe nucleus.

al., 1994; Romaniuk et al., 2001). 5-HT ${ }_{1 \mathrm{~A}}$ receptors located on serotonergic neuronal cell bodies and dendrites are the predominant somatodendritic autoreceptors of these neurons. Activation of the autoreceptors suppressed serotonergic neuronal activity (Sotelo et al., 1990; Sprouse and Aghajanian, 1987). Intra-DRN infusions of a 5-HT agonist showed anxiolytic effects in the light-dark box (Romaniuk et al., 2001), social interaction test (Higgins et al., 1992; Hogg et al., 1994), and elevated T maze test (Graeff et al., 1998). On the other hand, 5-HT ${ }_{1 \mathrm{~A}}$ knockout mice demonstrate increased anxiety in the open field test, elevated plus maze, elevated zero maze, and novelty-suppressed feeding test (Gross et al., 2000; Heisler et al., 1998; Parks et al., 1998; Ramboz et al., 1998). Taken together, in utero exposure to DEPs may cause impairment of $5-\mathrm{HT}_{1 \mathrm{~A}}$ receptor function in the DRN of male offspring. Another possibility is that DEP exposure alters 5-HT system function via effects on the 5-HT transporter. The 5-HT transporter is a critical regulator of 5-HT signaling, modulating serotonin function via reuptake from the peri-synaptic and synaptic spaces (Blakely et al., 1991; Ramamoorthy et al., 1993). In fact, 5-HT selective reuptake inhibitors (SSRI), which increase serotonergic tone, are first-line anxiolytic and antidepressant treatments (Ballenger, 1999; Kugaya et al., 2003). A genetic variant that reduces expression of 5-HT transporter has been associated with elevated levels of anxiety-like traits, susceptibility to affective disorder, and depressive symptoms (Arias et al., 2002; Collier et al., 1996; Lesch et al., 1996). These findings suggest that in utero exposure to DEPs could affect 5-HT transporter function in the DRN of male offspring, providing a possible mechanism underlying the increase in anxiety-like behavior.

Third, to investigate the mechanism underlying the increase in 5-HT levels in the DRN, we performed FosB immunostaining to examine 5-HT neuronal activity. We found that prenatal exposure to DEPs chronically increased FosB positive nuclei, including those within 5-HT immunopositive neurons of the DRN. Chronic Fos-related proteins such as FosB are relatively stable 
Fetal exposure to diesel exhaust particles induce anxiety-like behavior in male offspring

proteins that persist in the brain for long periods of time. For example, after chronic administration of cocaine or morphine, chronic Fos-related proteins remain detectable in the striatum and nucleus accumbens, respectively, for several weeks (Hiroi et al., 1997; Hope et al., 1994; Nye and Nestler, 1996). Such proteins are immunochemically related to $\triangle \mathrm{FosB}$, a truncated splice variant of FosB. The fos $B$ gene encodes two FosB proteins and five $\Delta$ FosB proteins, separated by molecular weight (Chen et al., 1997). Some FosB proteins maintain stable expression of the Fos family proteins (Chen et al., 1997). In a steady state, FosB proteins were rarely expressed, while $\Delta$ FosB proteins were stably-expressed (Carle et al., 2007; Hiroi et al., 1997; McClung et al., 2004; Nye and Nestler, 1996). Therefore, $\Delta$ FosB proteins were useful as indicators of chronic neural activity caused by long-lasting stimuli. Using repeated stimuli, $\Delta$ FosB proteins gradually accumulate to physiologically active levels (Chen et al., 1997). Notably, Cunningham et al. (2008) reported that three weeks of vagal nerve stimulation significantly increased $\Delta$ FosB positive cells in the cingulate cortex and DRN, which correlated with decreased time of immobility (depression-like behavior) in rats performing a forced swimming test. In addition, a further study found the amount of $\triangle$ FosB expressing 5-HT neurons in the DRN was increased in a time-dependent manner by vagal nerve stimulation (Dorr and Debonnel, 2006). These results indicate that the increase in FosB immunopositive cells in 5-HT neurons represented chronic activation of 5-HT neurons.

In our experimental design, the only artificial stimulus was restricted to prenatal DEP exposure, except for the weekly exchange of old cages in the rooms in which mice were reared. Therefore, prenatal exposure to DEPs was the most likely stimulus to be inducing chronic activation of DRN 5-HT neurons in this study. Anxiogenic drugs such as caffeine, and anxiety-related stimuli such as open field exposure and social defeat, have been demonstrated to activate a population of 5-HT neurons in the DRN, as has prenatal restraint stress (Hale et al., 2012; Miyagawa et al., 2011). The present study suggested that in utero exposure to DEPs altered developmental programming and increased susceptibility of the male offspring to anxiety-inducing external stimuli, which in turn more easily activate 5-HT neurons in the DRN of the DEP-exposed mice. A previous study reported that early postnatal stress induced abnormalities of anxiety-like behavior of rats in the elevated plus maze (Konno et al., 2007). They also found that the same behavior was observed in rats with raphe nucleus damage. In addition, male offspring of dams that experienced both PM exposure and nest material restriction (stress) displayed increased anxiety (Bolton et al., 2013). The results of the present study are compatible with, and supported by, those of the previous studies. Thus, future studies should focus on the changes in functional molecules involved in the development of 5-HT neurons.

In conclusion, prenatal exposure to DEPs resulted in chronically activated 5-HT neuronal activity in the DRN, and also exacerbated anxiety-like behaviors in the exposed male offspring.

\section{ACKNOWLEDGMENTS}

We are grateful to Dr. Keisuke Mizuo (Tokyo University of Science), Dr. Shinya Yanagita (Tokyo University of Science), Mr. Nozomu Moriya (Hyogo University of Health Sciences), Mrs. Mari Iwata (Tokyo University of Science) and Mr. Akira Sato (Tokyo University of Science) for experimental support. We also thank Mr. Tadashi Udagawa (Research Institute of Tuberculosis) for providing DEP samples. We would like to thank Editage (www.editage.jp) for English language editing. This research was supported in part by a Grant-in-Aid for Science Research from the Japan Society for the Promotion of Science (JSPS) and a grant from the Academic Frontier Project from the Ministry of Education, Culture, Sports, Science, and Technology of Japan. This work was supported by a Grant-in-Aid for JSPS Fellows (Satoshi Yokota, 22. 5895) and in part by a Grant-in-Aid for Science Research from the Ministry of Education, Culture, Sports, Science, and Technology of Japan. This work was also supported by a Grant-in-Aid for Health and Labor Sciences Research Grants, Research on Risk of Chemical Substances, from the Ministry of Health, Labor, and Welfare, and a Grant-in-Aid for MEXT-supported Program for the Strategic Research Foundation at Private Universities (Grant Number S1101015, 2011-2015).

Conflict of interest---- The authors declare that there is no conflict of interest.

\section{REFERENCES}

Amemiya, S., Yanagita, S., Suzuki, S., Kubota, N., Motoki, C., Otsuka, T., Nishijima, T. and Kita, I. (2010): Differential effects of background noise of various intensities on neuronal activation associated with arousal and stress response in a maze task. Physiol. Behav., 99, 521-528.

Arias, B., Arranz, M.J., Gasto, C., Catalan, R., Pintor, L., Gutierrez, B., Kerwin, R.W. and Fananas, L. (2002): Analysis of structural polymorphisms and $\mathrm{C}-1018 \mathrm{G}$ promoter variant of the 5-HT(1A) receptor gene as putative risk factors in major depression. Mol. Psychiatry, 7, 930-932. 
Ballenger, J.C. (1999): Current treatments of the anxiety disorders in adults. Biol. Psychiatry, 46, 1579-1594.

Barrett, J.E. and Vanover, K.E. (1993): 5-HT receptors as targets for the development of novel anxiolytic drugs: models, mechanisms and future directions. Psychopharmacology (Berl)., 112, 1-12.

Becerra, T.A., Wilhelm, M., Olsen, J., Cockburn, M. and Ritz, B. (2013): Ambient air pollution and autism in Los Angeles county, California. Environ. Health Perspect., 121, 380-386.

Blakely, R.D., Berson, H.E., Fremeau, R.T.Jr., Caron, M.G., Peek, M.M., Prince, H.K. and Bradley, C.C. (1991): Cloning and expression of a functional serotonin transporter from rat brain. Nature, 354, 66-70.

Bolton, J.L., Huff, N.C., Smith, S.H., Mason, S.N., Foster, W.M., Auten, R.L. and Bilbo, S.D. (2013): Maternal stress and effects of prenatal air pollution on offspring mental health outcomes in mice. Environ. Health Perspect., 121, 1075-1082.

Boulle, F., Pawluski, J.L., Homberg, J.R., Machiels, B., Kroeze, Y., Kumar, N., Steinbusch, H.W., Kenis, G. and Van den Hove, D.L. (2015): Prenatal stress and early-life exposure to fluoxetine have enduring effects on anxiety and hippocampal BDNF gene expression in adult male offspring. Dev. Psychobiol. [Epub ahead of print]

Campbell, B.M. and Merchant, K.M. (2003): Serotonin 2C receptors within the basolateral amygdala induce acute fear-like responses in an open-field environment. Brain Res., 993, 1-9.

Carle, T.L., Ohnishi, Y.N., Ohnishi, Y.H., Alibhai, I.N., Wilkinson, M.B., Kumar, A. and Nestler, E.J. (2007): Proteasome-dependent and -independent mechanisms for FosB destabilization: identification of FosB degron domains and implications for DeltaFosB stability. Eur. J. Neurosci., 25, 3009-3019.

Carobrez, A.P. and Bertoglio, L.J. (2005): Ethological and temporal analyses of anxiety-like behavior: the elevated plus-maze model 20 years on. Neurosci. Biobehav. Rev., 29, 1193-1205.

Chen, J., Kelz, M.B., Hope, B.T., Nakabeppu, Y. and Nestler, E.J. (1997): Chronic Fos-related antigens: stable variants of deltaFosB induced in brain by chronic treatments. J. Neurosci., 17, 4933-4941.

Collier, D.A., Stöber, G., Li, T., Heils, A., Catalano, M., Di Bella, D., Arranz, M.J., Murray, R.M., Vallada, H.P., Bengel, D., Müller, C.R., Roberts, G.W., Smeraldi, E., Kirov, G., Sham, P. and Lesch, K.P. (1996): A novel functional polymorphism within the promoter of the serotonin transporter gene: possible role in susceptibility to affective disorders. Mol. Psychiatry., 1, 453460.

Commons, K.G. (2008): Evidence for topographically organized endogenous 5-HT-1A receptor-dependent feedback inhibition of the ascending serotonin system. Eur. J. Neurosci., 27, 26112618.

Costa, S.K., Kumagai, Y., Brain, S.D., Teixeira, S.A., Varriano, A.A., Barreto, M.A., de Lima, W.T., Antunes, E., Muscará, M.N. and Costa, S.K. (2010): Involvement of sensory nerves and TRPV1 receptors in the rat airway inflammatory response to two environment pollutants: diesel exhaust particles (DEP) and 1,2naphthoquinone (1,2-NQ). Arch. Toxicol., 84, 109-117.

Cunningham, J.T., Mifflin, S.W., Gould, G.G. and Frazer, A. (2008): Induction of c-Fos and DeltaFosB immunoreactivity in rat brain by Vagal nerve stimulation. Neuropsychopharmacology, 33, 1884-1895.

Dorr, A.E. and Debonnel, G. (2006): Effect of vagus nerve stimulation on serotonergic and noradrenergic transmission. J. Pharmacol. Exp. Ther., 318, 890-898.

Escorihuela, R.M., Fernández-Teruel, A., Gil, L., Aguilar, R.,
Tobeña, A. and Driscoll, P. (1999): Inbred Roman high- and lowavoidance rats: differences in anxiety, novelty-seeking, and shuttlebox behaviors. Physiol. Behav., 67, 19-26.

Graeff, F.G., Guimarães, F.S., De Andrade, T.G. and Deakin, J.F. (1996): Role of 5-HT in stress, anxiety, and depression. Pharmacol. Biochem. Behav., 54, 129-141.

Graeff, F.G., Netto, C.F. and Zangrossi, H.Jr. (1998): The elevated T-maze as an experimental model of anxiety. Neurosci. Biobehav. Rev., 23, 237-246.

Gross, C., Santarelli, L., Brunner, D., Zhuang, X. and Hen, R. (2000): Altered fear circuits in 5-HT(1A) receptor KO mice. Biol. Psychiatry., 48, 1157-1163.

Hale, M.W., Shekhar, A. and Lowry, C.A. (2012): Stress-related serotonergic systems: implications for symptomatology of anxiety and affective disorders. Cell. Mol. Neurobiol., 32, 695-708.

Heisler, L.K., Chu, H.M., Brennan, T.J., Danao, J.A., Bajwa, P., Parsons, L.H. and Tecott, L.H. (1998): Elevated anxiety and antidepressant-like responses in serotonin 5-HT1A receptor mutant mice. Proc. Natl. Acad. Sci. USA, 95, 15049-15054.

Higgins, G.A., Jones, B.J. and Oakley, N.R. (1992): Effect of 5-HT1A receptor agonists in two models of anxiety after dorsal raphe injection. Psychopharmacology (Berl)., 106, 261-267.

Hiroi, N., Brown, J.R., Haile, C.N., Ye, H., Greenberg, M.E. and Nestler, E.J. (1997): FosB mutant mice: loss of chronic cocaine induction of Fos-related proteins and heightened sensitivity to cocaine's psychomotor and rewarding effects. Proc. Natl. Acad. Sci. USA, 94, 10397-10402.

Hogg, S., Andrews, N. and File, S.E. (1994): Contrasting behavioural effects of 8-OH DPAT in the dorsal raphé nucleus and ventral hippocampus. Neuropharmacology, 33, 343-348.

Holmes, A., Parmigiani, S., Ferrari, P.F., Palanza, P. and Rodgers, R.J. (2000): Behavioral profile of wild mice in the elevated plusmaze test for anxiety. Physiol. Behav., 71, 509-516.

Hope, B.T., Nye, H.E., Kelz, M.B., Self, D.W., Iadarola, M.J., Nakabeppu, Y., Duman, R.S. and Nestler, E.J. (1994): Induction of a long-lasting AP-1 complex composed of altered Foslike proteins in brain by chronic cocaine and other chronic treatments. Neuron, 13, 1235-1244.

Hu, M., Richard, J.E., Maliqueo, M., Kokosar, M., Fornes, R., Benrick, A., Jansson, T., Ohlsson, C., Wu, X., Skibicka, K.P. and Stener-Victorin, E. (2015): Maternal testosterone exposure increases anxiety-like behavior and impacts the limbic system in the offspring. Proc. Natl. Acad. Sci. USA, 112, 14348-14353.

Kalkbrenner, A.E., Windham, G.C., Serre, M.L., Akita, Y., Wang, X., Hoffman, K., Thayer, B.P. and Daniels, J.L. (2015): Particulate matter exposure, prenatal and postnatal windows of susceptibility, and autism spectrum disorders. Epidemiology, 26, 30-42.

Kelly, K.J., Donner, N.C., Hale, M.W. and Lowry, C.A. (2011): Swim stress activates serotonergic and nonserotonergic neurons in specific subdivisions of the rat dorsal raphe nucleus in a temperature-dependent manner. Neuroscience, 197, 251-268.

Konno, K., Matsumoto, M., Togashi, H., Yamaguchi, T., Izumi, T., Watanabe, M., Iwanaga, T. and Yoshioka, M. (2007): Early postnatal stress affects the serotonergic function in the median raphe nuclei of adult rats. Brain Res., 1172, 60-66.

Kugaya, A., Seneca, N.M., Snyder, P.J., Williams, S.A., Malison, R.T., Baldwin, R.M., Seibyl, J.P. and Innis, R.B. (2003): Changes in human in vivo serotonin and dopamine transporter availabilities during chronic antidepressant administration. Neuropsychopharmacology., 28, 413-420.

Lesch, K.P., Bengel, D., Heils, A., Sabol, S.Z., Greenberg, B.D., Petri, S., Benjamin, J., Müller, C.R., Hamer, D.H. and Murphy, 
Fetal exposure to diesel exhaust particles induce anxiety-like behavior in male offspring

D.L. (1996): Association of anxiety-related traits with a polymorphism in the serotonin transporter gene regulatory region. Science, 274, 1527-1531.

Lucki, I. (1998): The spectrum of behaviors influenced by serotonin. Biol. Psychiatry., 44, 151-162.

Maier, S.F., Grahn, R.E., Kalman, B.A., Sutton, L.C., Wiertelak, E.P. and Watkins, L.R. (1993): The role of the amygdala and dorsal raphe nucleus in mediating the behavioral consequences of inescapable shock. Behav. Neurosci., 107, 377-388.

McClung, C.A., Ulery, P.G., Perrotti, L.I., Zachariou, V., Berton, O. and Nestler, E.J. (2004): DeltaFosB: a molecular switch for long-term adaptation in the brain. Brain Res. Mol. Brain Res., 132, 146-154.

Miyagawa, K., Tsuji, M., Fujimori, K., Saito, Y. and Takeda, H. (2011): Prenatal stress induces anxiety-like behavior together with the disruption of central serotonin neurons in mice. Neurosci. Res., 70, 111-117.

Morgan, M.A. and Pfaff, D.W. (2001): Effects of estrogen on activity and fear-related behaviors in mice. Horm. Behav., 40, 472482.

Mosienko, V., Bert, B., Beis, D., Matthes, S., Fink, H., Bader, M. and Alenina, N. (2012): Exaggerated aggression and decreased anxiety in mice deficient in brain serotonin. Transl. Psychiatry., 2, e122.

Nye, H.E. and Nestler, E.J. (1996): Induction of chronic Fos-related antigens in rat brain by chronic morphine administration. Mol. Pharmacol., 49, 636-645.

Parks, C.L., Robinson, P.S., Sibille, E., Shenk, T. and Toth, M. (1998): Increased anxiety of mice lacking the serotonin1 A receptor. Proc. Natl. Acad. Sci. USA, 95, 10734-10739.

Paul, E.D., Hale, M.W., Lukkes, J.L., Valentine, M.J., Sarchet, D.M. and Lowry, C.A. (2011): Repeated social defeat increases reactive emotional coping behavior and alters functional responses in serotonergic neurons in the rat dorsal raphe nucleus. Physiol. Behav., 104, 272-282.

Paxinos, G. and Franlin, K.B.J. (2001): The mouse brain in stereotaxic coordinates. Academic Press, 2.

Perera, F.P., Tang, D., Wang, S., Vishnevetsky, J., Zhang, B., Diaz, D., Camann, D. and Rauh, V. (2012): Prenatal polycyclic aromatic hydrocarbon (PAH) exposure and child behavior at age 6-7 years. Environ. Health Perspect., 120, 921-926.

Ramamoorthy, S., Bauman, A.L., Moore, K.R., Han, H., Yang-Feng, T., Chang, A.S., Ganapathy, V. and Blakely, R.D. (1993): Antidepressant- and cocaine-sensitive human serotonin transporter: molecular cloning, expression, and chromosomal localization. Proc. Natl. Acad. Sci. USA, 90, 2542-2546.

Ramboz, S., Oosting, R., Amara, D.A., Kung, H.F., Blier, P., Mendelsohn, M., Mann, J.J., Brunner, D. and Hen, R. (1998): Serotonin receptor $1 \mathrm{~A}$ knockout: an animal model of anxiety-related disorder. Proc. Natl. Acad. Sci. USA, 95, 14476-14481.

Ren-Patterson, R.F., Cochran, L.W., Holmes, A., Lesch, K.P., Lu, B. and Murphy, D.L. (2006): Gender-dependent modulation of brain monoamines and anxiety-like behaviors in mice with genetic serotonin transporter and BDNF deficiencies. Cell. Mol. Neurobiol., 26, 755-780.

Romaniuk, A., Koprowska, M., Krotewicz, M., Strzelczuk, M. and Wieczorek, M. (2001): Effects of 8-OHDPAT administration into the dorsal raphe nucleus and dorsal hippocampus on fear behavior and regional brain monoamines distribution in rats. Behav. Brain Res., 120, 47-57.

Silverman, D.T., Samanic, C.M., Lubin, J.H., Blair, A.E., Stewart, P.A., Vermeulen, R., Coble, J.B., Rothman, N., Schleiff, P.L., Travis, W.D., Ziegler, R.G., Wacholder, S. and Attfield, M.D.
(2012): The Diesel Exhaust in Miners study: a nested case-control study of lung cancer and diesel exhaust. J. Natl. Cancer Inst., 104, 855-868.

Solati, J., Kleehaupt, E., Kratz, O., Moll, G.H. and Golub, Y. (2015): Inverse effects of lipopolysaccharides on anxiety in pregnant mice and their offspring. Physiol. Behav., 139, 369-374.

Sotelo, C., Cholley, B., El Mestikawy, S., Gozlan, H. and Hamon, M. (1990): Direct Immunohistochemical Evidence of the Existence of 5-HT1A Autoreceptors on Serotoninergic Neurons in the Midbrain Raphe Nuclei. Eur. J. Neurosci., 2, 1144-1154.

Spannuth, B.M., Hale, M.W., Evans, A.K., Lukkes, J.L., Campeau, S. and Lowry, C.A. (2011): Investigation of a central nucleus of the amygdala/dorsal raphe nucleus serotonergic circuit implicated in fear-potentiated startle. Neuroscience, 179, 104-119.

Sprouse, J.S. and Aghajanian, G.K. (1987): Electrophysiological responses of serotoninergic dorsal raphe neurons to 5-HT1A and 5-HT1B agonists. Synapse., 1, 3-9.

Sugamata, M., Ihara, T., Takano, H., Oshio, S. and Takeda, K. (2006): Maternal diesel exhaust exposure damages newborn murine brains. J. Health Sci., 52, 82-84.

Suzuki, T., Oshio, S., Iwata, M., Saburi, H., Odagiri, T., Udagawa, T., Sugawara, I., Umezawa, M. and Takeda, K. (2010): In utero exposure to a low concentration of diesel exhaust affects spontaneous locomotor activity and monoaminergic system in male mice. Part Fibre Toxicol., 7, 7.

Takeda, H., Tsuji, M. and Matsumiya, T. (1998): Changes in headdipping behavior in the hole-board test reflect the anxiogenic and/or anxiolytic state in mice. Eur. J. Pharmacol., 350, 21-9.

Tsuji, M., Takeda, H. and Matsumiya, T. (2000): Different effects of 5-HT1A receptor agonists and benzodiazepine anxiolytics on the emotional state of naive and stressed mice: a study using the hole-board test. Psychopharmacology (Berl)., 152, 157-166.

Walf, A.A. and Frye, C.A. (2007): The use of the elevated plus maze as an assay of anxiety-related behavior in rodents. Nat. Protoc., 2, 322-328.

Wichmann, H.E. (2007): Diesel exhaust particles. Inhal Toxicol., 19, 241-244.

Yanagita, S., Amemiya, S., Suzuki, S. and Kita, I. (2007): Effects of spontaneous and forced running on activation of hypothalamic corticotropin-releasing hormone neurons in rats. Life Sci., 80, 356-363.

Yokota, S., Hori, H., Umezawa, M., Kubota, N., Niki, R., Yanagita, S. and Takeda, K. (2013a): Gene expression changes in the olfactory bulb of mice induced by exposure to diesel exhaust are dependent on animal rearing environment. PLoS One., 8, e70145.

Yokota, S., Mizuo, K., Moriya, N., Oshio, S., Sugawara, I. and Takeda, K. (2009): Effect of prenatal exposure to diesel exhaust on dopaminergic system in mice. Neurosci Lett., 449, 38-41.

Yokota, S., Moriya, N., Iwata, M., Umezawa, M., Oshio, S. and Takeda, K. (2013b): Exposure to diesel exhaust during fetal period affects behavior and neurotransmitters in male offspring mice. J. Toxicol. Sci., 38, 13-23.

Yokota, S., Oshio, S., Moriya, N. and Takeda, K. (2016): Social Isolation-Induced Territorial Aggression in Male Offspring is Enhanced by Exposure to Diesel Exhaust during Pregnancy. PLoS One., 11, e0149737.

Yokota, S., Sato, A., Umezawa, M., Oshio, S. and Takeda, K. (2015): In utero exposure of mice to diesel exhaust particles affects spatial learning and memory with reduced N-methyl-daspartate receptor expression in the hippocampus of male offspring. Neurotoxicology, 50, 108-115. 